\title{
Study on the Impact of Filter Layer Permeability on Revetment Top Layer Stability under Wave Action
}

\author{
Liehong Ju ${ }^{1}$, Junning Pan ${ }^{1}$ and Chengrui Liu ${ }^{2}$ \\ 1. Nanjing Hydraulic Research Institute, Nanjing 210024, China \\ 2. Hehai University, Nanjing 210029, China
}

\begin{abstract}
In the design of revetment engineering under wave action, to resist the wave action, the pattern of top layer-filter layer-core (subsoil) is often adopted. In general, the structure of top layer is usually single discrete blocks, typically accropode blocks, four-leg square hollow blocks and barrier boards, and also acropode, riprap, paved rock blocks or concrete slabs with smaller waves. Such top layer has been provided with many research findings on its stability and is widely used in engineering. Setting a filter layer between the top layer and the lower dike core mainly has two functions: (1) giving certain permeability, to minimize the hydrodynamic load directly acting on the lower foundation soil; (2) giving certain hydraulic tightness, to prevent fine sediment of the lower foundation soil from being washed out. This paper is focused on a special filter layer with geotextile as its upper structure and coarse aggregate as its lower structure. By simulating geotextile with different permeability and coarse aggregate with different size, the pressure of top of cover layer and the down side of the geotextile is tested under wave actions, and compared with theoretical analysis, in this way, how the permeability of geotextile impacts the stability of top layer is studied. The research shows that when the filter layer under the geotextile has high permeability and the geotextile's permeability gets poorer, the uplift force to geotextile and the top layer will be increased under wave action, which will cause damage to the top layer when it is greater than the vertical component of the underwater gravity along the slope surface.
\end{abstract}

Key words: Revetment, wave, filter layer, geotextile, permeability, uplift force.

\section{Introduction}

The revetment engineering for estuary, inland lake, reservoir, some channels and inland river are always under the action of wave and flow. To prevent damage caused by this, cover layer-filter layer-subsoil is often adopted in revetment design. In the cover layer-filter layer-subsoil structure, the external top layer is generally rocks, blocks or asphalt, bearing the direct action of wave and water flow and increasing the lower layer ballast. The filter layer is beneath the top layer which is usually single-layer or multi-layer gravels and sand, providing support for the top layer. For permeable structure, the filter layer, on one hand, further relieves the wave and flow action on subsoil; on the other hand, it prevents the undermining of subsoil through the decrease of its geometric bore

Corresponding author: Liehong Ju, Ph.D., research field: coastal engineering. diameter. As the geotexitile has a small bore diameter and is well permeable, it is widely adopted in filter layer.

Most of geotextiles are placed between the sand layer and soil layer of the filter layer, but some are between the top layer and sand layer [1, 2]. In a reservoir dike project located in northern China, in order to prevent storm damage slope, top layer-geotextile-sand layer-subsoil is adopted, after many years suffered sudden damage after a major storm. Field investigation shows that geotextile below the top layer is clogged. Experiments show that this may be the cause of the dike failure. For such a structure, the permeability of filter layer has a great influence on the stability of top layer under wave action. In this paper, by simulating geotextile with different permeability and coarse aggregate with different size, the pressure of top of cover layer and 
the down side of the geotextile have been tested under wave actions, and compared with theoretical analysis, in this way, how the permeability of geotextile impacts the stability of top layer is studied.

Schiereck [3], de Groot [4], Burger [5], Bezuijen and Breteler [6] have made a lot of research about how the permeability of filter layer affects the top layer stability. This thesis is based on these studies conducted by these scholars.

The internal and external pressure difference caused by different permeability of top layer and filter layer is usually reflected by so called leakage length $\Lambda$ :

$$
\Lambda=\sqrt{\frac{k_{F} d_{F} d_{T}}{k_{T}}}
$$

where: $\quad k_{F}$, the permeability of filer layer;

$k_{T}$, the permeability of top layer;

$d_{F}$, the thickness of filer layer;

$d_{F}$, the thickness of top layer.

According to previous studies, the difference of pressure between top layer and filer layer w can be written as Eq. (2), and the parameters are defined in Fig. 1.

$$
\begin{aligned}
\phi_{w}= & \left(\frac{1}{2} \Lambda \cos \alpha \tan \theta\left(1-\exp \left(-\frac{\phi_{b}}{\Lambda \cos \alpha \tan \theta}\right)\right)+\frac{1}{2} \Lambda \sin \alpha\right) \\
& \cdot\left(1-\exp \left(\frac{-2 z_{1}}{\Lambda \sin \alpha}\right)\right)
\end{aligned}
$$

where: $\quad b$, wave potential;

$z_{1}$, phreatic lever in filter layer;

$\alpha$, angle of slope;

$\theta$, angle between wave potential line and

vertical line of slope.

\section{Physical Modelling Experiment}

The physical modelling experiment is made in a wave tank which is $60 \mathrm{~m}$ in length, $1.8 \mathrm{~m}$ in width and $1.6 \mathrm{~m}$ in height, and is equipped with ventilation, wave and flow equipment. Wave simulation system is the $\mathrm{AWACS}^{2}$, wave generation and secondary reflection absorption system manufactured by Danish Hydraulic Institute. Wave height is measured by capacitance wave-height gauge, wave pressure is measured by pressure transducer.

Fig. 2 shows the cross-section of the slope in the experiment: The slope ratio is $1: 3$, the top layer is covered with blocks (length $100 \mathrm{~mm}$, width $100 \mathrm{~mm}$, thickness $14 \mathrm{~mm}$ ) with 5 hole diameter of $18 \mathrm{~mm}$, which is placed on the geotextile. Sand is used in filter layer, with a thickness of $50 \mathrm{~mm}$, beneath the filer layer is embankment subsoil. The test water depth is $500 \mathrm{~mm}$.

Table 1 shows the wave parameters for tests, including five kinds of wave periods and five kinds of wave height, where $\xi=\tan \alpha / \sqrt{H / L_{0}}$ ( $\xi$ Irribarren parameters, or wave breaking parameters; $\alpha$, angle of slope; $H$ wave height; $L_{0}$ wave length in deep water). Only regular wave is tested in this experiment. Two kinds of short silk non-woven geotextile with synthetic fibers are used for tests. Table 2 shows the parameters of geotextile and filter layer for tests $(k$ permeability coefficient, $h$ thickness, $d_{50}$ median particle size).

Pressure sensors mounted on the block and in the sand below the geotextile every $100 \mathrm{~mm}$ along the slope, there are 11 measure vertical sections altogether,

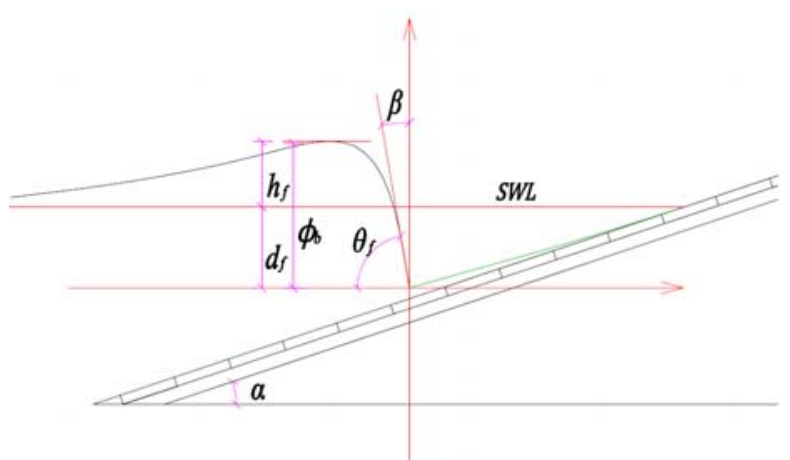

Fig. 1 Illustration of the symbols in Eq. (2).

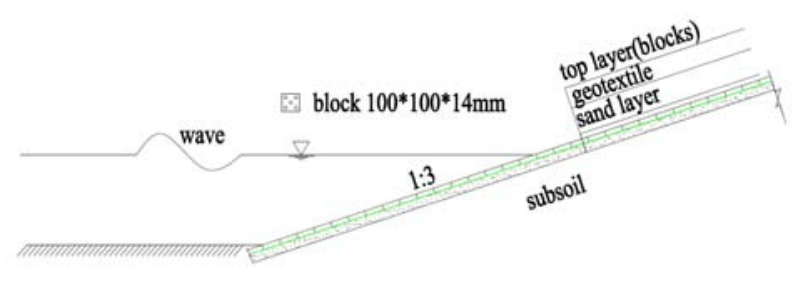

Fig. 2 Sectional view of slope in the experiment. 
Table 1 Wave conditions in the experiment.

\begin{tabular}{llllllllll}
\hline $\mathrm{T}=1.2 \mathrm{~s}$ & \multicolumn{3}{c}{$\mathrm{T}=1.4 \mathrm{~s}$} & \multicolumn{3}{c}{$\mathrm{T}=1.6 \mathrm{~s}$} & $\mathrm{~T}=1.8 \mathrm{~s}$ & $\mathrm{~T}=2.4 \mathrm{~s}$ \\
$\mathrm{H}(\mathrm{cm})$ & $\xi$ & $\mathrm{H}(\mathrm{cm})$ & $\xi$ & $\mathrm{H}(\mathrm{cm})$ & $\xi$ & $\mathrm{H}(\mathrm{cm})$ & $\xi$ & $\mathrm{H}(\mathrm{cm})$ & $\xi$ \\
9.8 & 1.57 & 10.2 & 1.85 & 10.1 & 2.14 & 10.3 & 2.38 & 11.6 & 2.87 \\
12.0 & 1.39 & 11.9 & 1.71 & 11.9 & 1.97 & 12.2 & 2.18 & 14.0 & 2.62 \\
14.0 & 1.39 & 13.9 & 1.58 & 14.2 & 1.80 & 13.9 & 2.04 & 16.3 & 2.42 \\
15.6 & 1.31 & 16.0 & 1.46 & 16.0 & 1.69 & 16.3 & 1.88 & 19.0 & 2.24 \\
17.8 & 1.21 & 18.3 & 1.36 & 18.1 & 1.59 & 18.3 & 1.78 & 22.2 & 2.08 \\
20.4 & 1.12 & 20.0 & 1.30 & 20.0 & 1.51 & 19.9 & 1.70 & 25.3 & 1.95 \\
\hline
\end{tabular}

Table 2 Geotextile and filter layer in the experiment.

\begin{tabular}{llll}
\hline & Parameters & Kind 1 & Kind 2 \\
Material & Staple fiber geotextile & woven geotextile \\
Geotextile & Weight $\left(\mathrm{g} / \mathrm{m}^{2}\right)$ & 80 & 200 \\
& $\mathrm{k}(\mathrm{cm} / \mathrm{s})$ & $3.5 \times 10^{-2}$ & $3.2 \times 10^{-1}$ \\
& $\mathrm{~h}(\mathrm{~mm})$ & $0.4 \times 2$ & 2.0 \\
$\mathrm{Material}$ & Sand & Gravel \\
Filter layer & $\mathrm{k}(\mathrm{cm} / \mathrm{s})$ & $1.0 \times 10^{-2}$ & $1.0 \times 10^{-1}$ \\
& $\mathrm{~h}(\mathrm{~mm})$ & 50 & 50 \\
\hline & $\mathrm{d}_{50}(\mathrm{~mm})$ & 0.37 & 2.73 \\
\hline
\end{tabular}

$k$, permeability coefficient; $d_{50}$, median particle size; $h$, thickness.

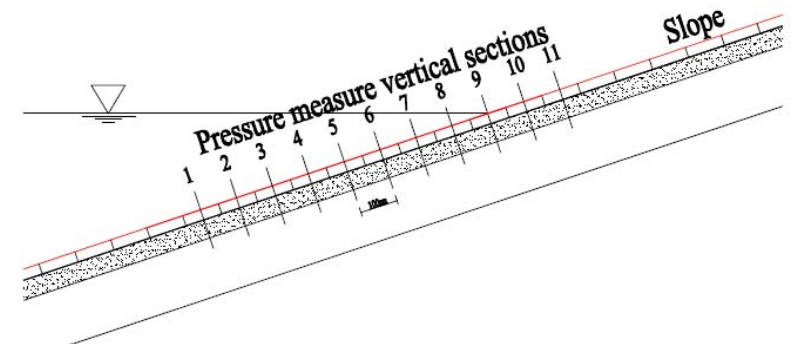

Fig. 3a Pressure measure vertical sections along the slope.

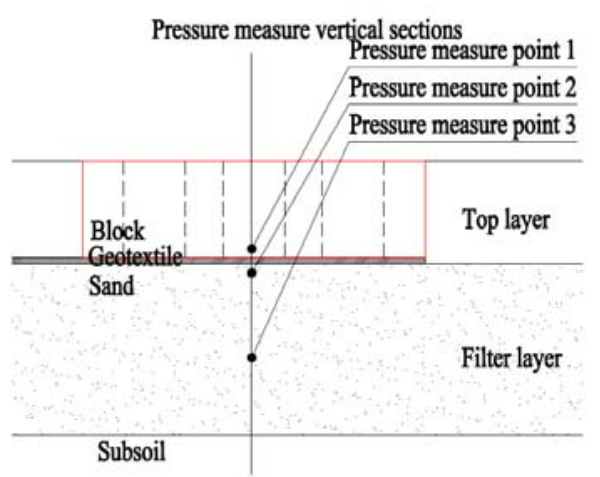

Fig. 3b Pressure measure points in one vertical section.

as shown in Fig. 3. There are three points in every measure vertical section to measure the pressure of different layer: pressure 1, at the down side of the top layer (upper side of the geotextile); pressure 2, lower part of the geotextile (upper part of the sand layer); pressure 3, lower part of the sand layer under wave action. All sensors measure pressure simultaneously, the measured data are collected by the computer.

The pressure sensor is a silicon piezoresistive pressure sensor, its background pressure is atmospheric pressure. When the ambient temperature is between $5 \sim 30{ }^{\circ} \mathrm{C}$, the sensitivity coefficient of variation of the sensor is not more than $0.5 \%$ of full scale. The other parameters of the pressure sensor are:

Frequency response of the sensor: $>1,000 \mathrm{~Hz}$;

Sensor range: $10 \mathrm{kPa}$;

Resolution: $10 \mathrm{~Pa}$;

Error: $< \pm 1 \%$ F.S.;

Sensor input voltage: $\pm 12 \mathrm{~V}$;

The output signal voltage sensor: $-10 \mathrm{~V} \sim+10 \mathrm{~V}$.

\section{Experiment Result Analysis}

Fig. 4 shows the measured pressure 1 variation during a wave period, each line is a moment of the pressure measured by the 11 vertical sections along the slope (Test condition: wave height $\mathrm{H}=12 \mathrm{~cm}$, wave 


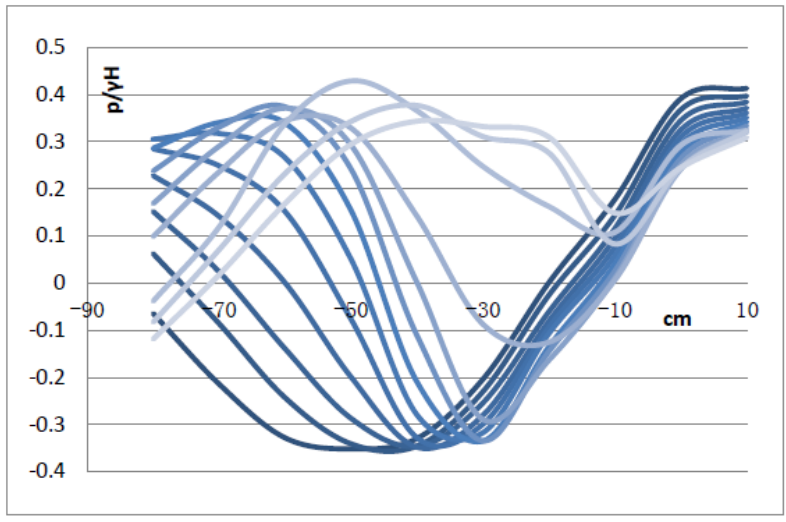

(a) From $t=0 \mathrm{~s}$ to $0.6 \mathrm{~s}$ during a wave period

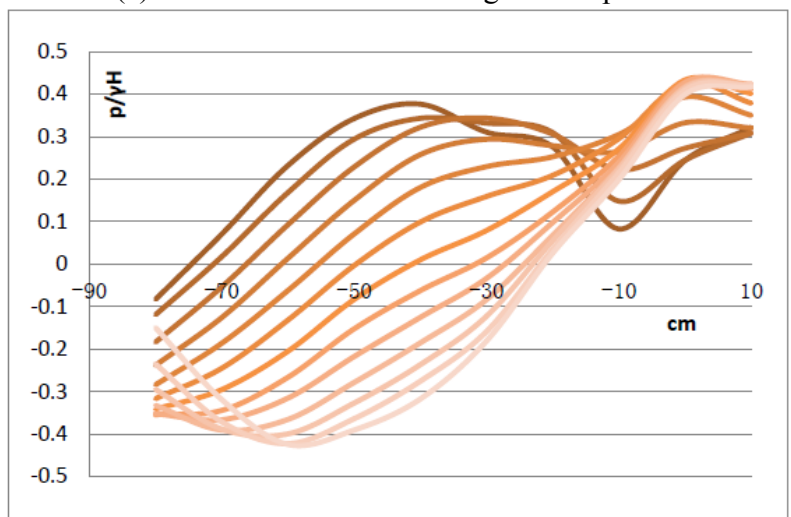

(b) From $t=0.6 \mathrm{~s}$ to $1.2 \mathrm{~s}$ during a wave period

Fig. 4 Measured pressure variation during a wave period along the slope.

(Test condition: $H=12 \mathrm{~cm}, T=1.2 \mathrm{~s} ; t=0 \sim 1.2 \mathrm{~s}, \Delta t=0.05 \mathrm{~s}$ ).

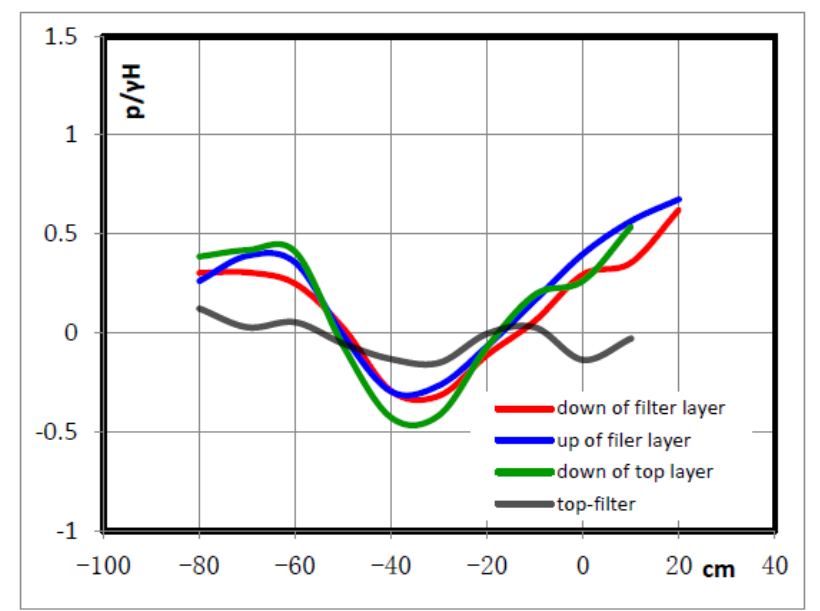

Fig. 5 Pressure measured by different point versus time during a wave period.

(Test condition: $H=12 \mathrm{~cm}, T=1.2 \mathrm{~s} ; t=0.24 \mathrm{~s}$ ).

period $\mathrm{T}=1.2 \mathrm{~s}$; time interval $\Delta \mathrm{t}=0.05 \mathrm{~s}$ ). We can see the pressure changing along the slope by time interval $\Delta \mathrm{t}=0.05 \mathrm{~s}$ during a wave period. When the negative pressure is the maximum generally considered

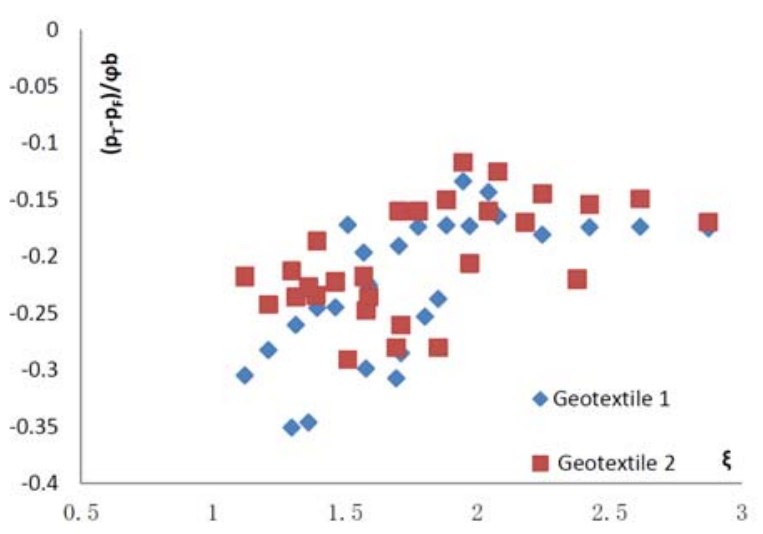

(a) Sand filer layer

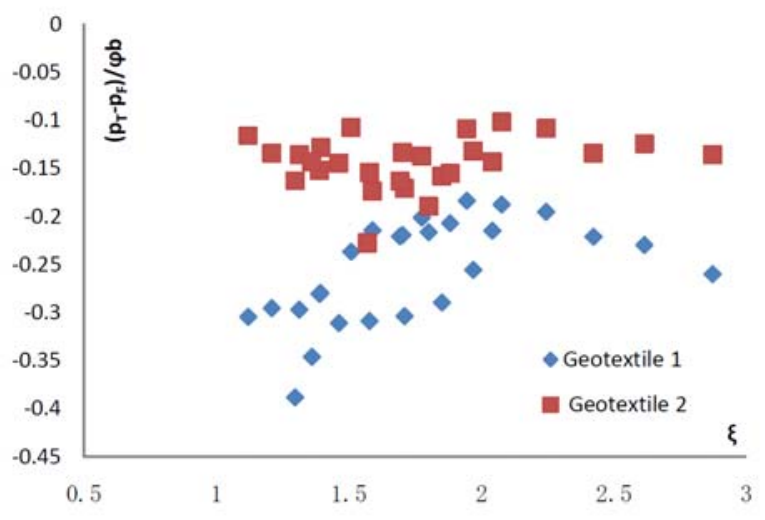

(b) Grave 1 filer layer

Fig. 6 Maximum of relative net pressure $\left(p_{T}-p_{F}\right) / \gamma H$ versus $\xi$.

the moment when the block stability is the worst.

Fig. 5 shows pressure of the different measure point versus time: the green line, pressure of the lower part of top layer (pressure 1); the blue line, upper part of sand layer (pressure 2); the red line, lower part of sand layer (pressure 3). The gray line is the pressure difference between pressure 1 and pressure 2 (Test condition: $H=12 \mathrm{~cm}, T=1.2 \mathrm{~s} ; t=0 \sim 0.6 \mathrm{~s}, \Delta t=0.05$ s).

Fig. 5 shows that the negative pressure of top layer is smaller than the filter layer, so there is net pressure point from filter layer to the outside, which causes the uplift force to the geotextile and the top blocks.

There is a max net pressure among the 1 9 vertical sections for each test, call it $p_{T-} p_{F}\left(p_{F}\right.$ pressure $2 ; p_{T}$ pressure 1). Fig. 6 shows this $\left(p_{T}-p_{F}\right) / \gamma H(\gamma$, proportion of water; $H$, wave height) versus $\xi$.

When the filter layer of sand and gravel were 
selected, and the geotextile 1 and the geotextile 2 were selected to be tested, all of the test results of $\left(p_{T}-p_{F}\right) / \gamma H$ versus $\xi$ are shown in Fig. 5. Through comparison, it's found that test data of max net pressure using geotextile 1 are greater than that using geotextile 2 which permeability decreases, and such difference is more obvious when the filter layer is gravel.

\section{Computing of Pressure in Filter Layer}

Physical model tests show that the permeability change of geotextile and filer layer can cause an increase of lift force to the geotextile and top layer (blocks) under wave action, when the waves fall back to the trough, the net pressure point to outside from the filter reaches the maximum, at this moment, if the lift force is greater than the vertical component of block gravity along the slope surface, the geotextile and block movement will occur. The next study will analyze the impact of the lift force through the geotextile and filer layer permeability change.

Water flow movement in filter layer is considered to comply with Forchheimer formula:

$$
I=a u+b u^{2}+c u^{\prime}
$$

In order to study the size of the coefficients in the formula, van Gent [7] conducted a very detailed research. The results of study show that the laminar flow coefficient is different from the turbulent coefficient in the formula under the action of steady flow and reciprocating flow. For reciprocating flow, turbulent influence is even greater. In the meantime, the research shows that the acceleration item has little influence on general gravel filter layer. Here because the $d_{50}$ of sand and gravel is much smaller, we assume no inertial term and acceleration term impact $(b=0 ; c$ $=0$ ). There are also the following assumptions:

(1) The subsoil is impermeable compared to the filter layer;

(2) The flow in the filter layer can be considered as one-dimensional, physically linear (or linearized) flow in the direction of the slope;
(3) The permeability of the top layer and geotextile $\left(\mathrm{k}_{\mathrm{T}}\right)$ is assumed to be homogeneous;

(4) The phreatic level in the filter layer is fixed.

Supposing that wave pressure in top layer is $p_{T}(x, t)$ and water pressure in filter layer is $p_{F}(x, t)$, if the seepage flowing through the top layer complies with the Darcy's Law, the seepage velocity along the $d x$ section of the slope is:

$$
v=k_{T} \frac{p_{T}(x, t)-p_{F}(x, t)}{D}
$$

Supposing that the bottom $(x=0)$ of filter layer is impermeable, the seepage discharge within $x$ is:

$$
Q=\int_{0}^{x} v d x
$$

When the water penetrating the top layer makes horizontal movement in the filter layer, the seepage discharge in the filter layer at $x$ is:

$$
Q=-k_{F} \frac{\partial P_{F}(x, t)}{\partial x} d
$$

From Eqs. (8) and (9), it can be concluded:

$$
\frac{\partial^{2} P_{F}}{\partial x^{2}}=-\frac{k_{T}}{D d k_{F}}\left(p_{T}-p_{F}\right)
$$

Here we can use the definition of leakage length:

$$
\Lambda=\sqrt{\frac{k_{F} d D}{k_{T}}}
$$

Then

$$
\frac{\partial^{2} P_{F}}{\partial x^{2}}=-\frac{\left(p_{T}-p_{F}\right)}{\Lambda^{2}}
$$

By this method, we get the same formula obtained by Wolsink. As regards Eq. (7.2), and compared with experimental results, here we make different assumptions to the top pressure $p_{T}(x, t)$ (See Fig. 7):

$$
p_{T}(x, t)=\frac{\phi_{T}}{2} \sin \frac{2 \pi x}{l} \sin \frac{2 \pi t}{T} \quad(0<\mathrm{x}<1 / 2)
$$

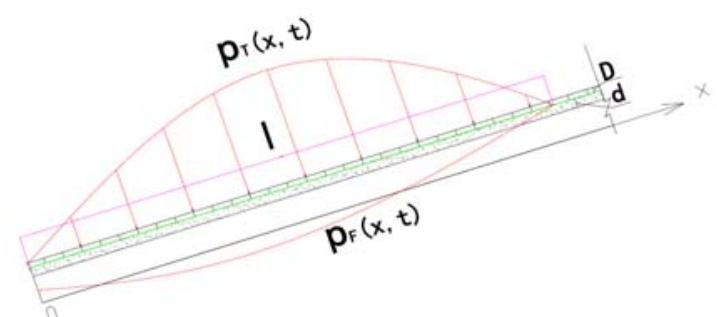

Fig. 7 Pressure Distribution on top layer along the slope which assumed in Eq. (9). 
In consideration of the boundary condition, when $x$ $=0$, it can be drawn that:

$$
\frac{\partial p_{F}}{\partial x}=0
$$

and, when $x=1 / 2$, without regard to the boundary's influence on outflow, supposing:

$$
\frac{\partial^{2} p_{F}}{\partial x^{2}}=0
$$

According to these conditions, water pressure distribution in filter layer is:

$$
\begin{aligned}
p_{F}= & \frac{\phi_{T}}{2\left(1+\frac{4 \pi^{2} \Lambda^{2}}{l^{2}}\right)}\left[\sin \frac{2 \pi x}{l}-\frac{2 \pi}{l} \frac{\Lambda}{1+e^{l / \Lambda}} \exp \left(\frac{x}{\Lambda}\right)\right. \\
& \left.+\frac{2 \pi}{l} \frac{e^{l / \Lambda} \Lambda}{1+e^{l / \Lambda}} \exp \left(-\frac{x}{\Lambda}\right)\right] \sin \frac{2 \pi t}{T}
\end{aligned}
$$

Comparing Eq. (12) with Eq. (9), we can see that the main difference between the top layer pressure and filter layer pressure is $1 /\left(1+4 \pi^{2} \Lambda^{2} / l^{2}\right)$. When $\Lambda$ is relatively high (the permeability of filter layer is better than that of top layer and geotextile), the pressure in filter layer is smaller than that of top layer, then the net pressure from the filer layer to outside is larger and the uplift force to the block and geotextile is greater, vice versa. According to the experiment, the length 1 along the slope is related to the wave height $H$ and wave length $L$.

When $\Lambda=0.5, \Lambda=0.2$ and $\Lambda=0.05$ (when $l=1 \mathrm{~m}$ ), the pressure $p_{\mathrm{F}}$ in filter layer and the pressure $\mathrm{p}_{T}-\mathrm{p}_{F}$ between the top layer and filter layer which calculated by Eq. (12) are shown in Fig. 9(a-c). Because the filter layer is assumed to be impermeable at the bottom end of slope $(x=0)$, there is negative pressure at the end of slope $(x=0)$ which point inside to the filter layer, and the position where $p_{T}-p_{F}=0$ is away from the end of slope $(x=0)$. The pressure $\mathrm{p}_{\mathrm{F}}(\mathrm{x}=0)$ at the bottom end of slope versus $\Lambda$ see Fig. $9(\mathrm{~d}), \mathrm{p}_{F}(\mathrm{x}=0)$ meet the maximum when $\Lambda=0.16$.

The actual boundary condition at another end of $\operatorname{slope}(x=0.51)$ is different from that assumed in Eq. (11). In fact, along the slope where $x>0.51$, it makes $\partial^{2} p_{F} / \partial x^{2} \neq 0$ that the water level in the filter layer grows up and down. Under the positive pressure action
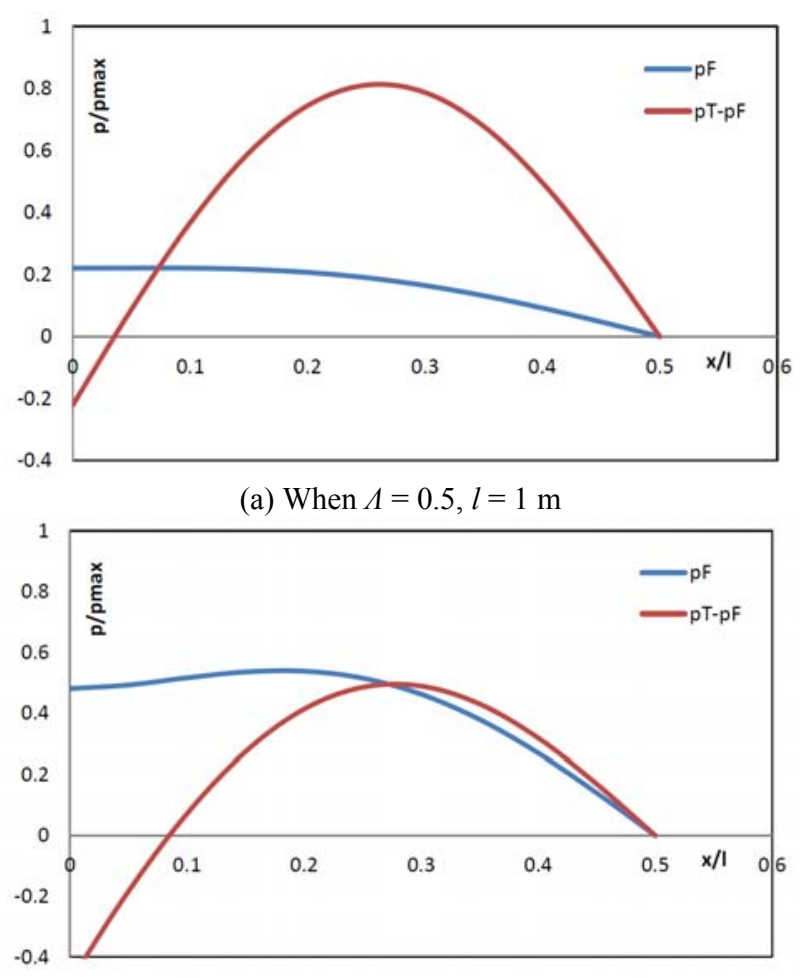

(b) When $\Lambda=0.2, l=1 \mathrm{~m}$

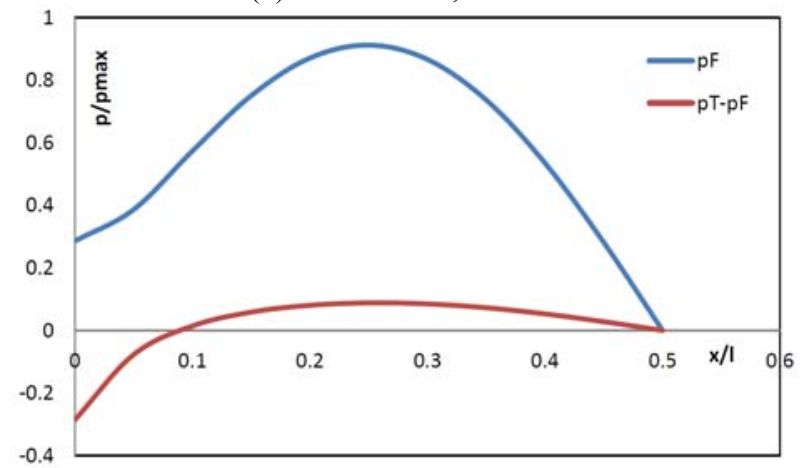

(c) When $\Lambda=0.05, l=1 \mathrm{~m}$

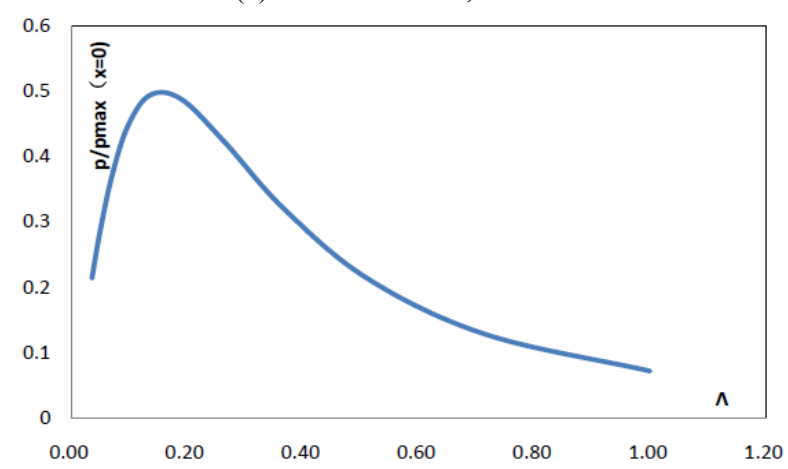

(d) Relative pressure $p_{F}(x=0)$ versus $\Lambda$

Fig. 9 Relative pressure $\left(p / p_{\max }, p_{\max }=\phi_{T} / 2\right)$ calculated by Eq. (12). 
(wave crest), the water level inside the filter layer is growing up, at the time when under negative pressure action (wave trough), because of the delay of water flow out of filter layer, it makes the initial pressure $p_{F}(\mathrm{x}=1 / 2)$ greater than 0 , which will cause the uplift force to the top layer and geotextile increase, this should be taken into account additionally.

\section{Conclusions}

For top layer-filter layer-subsoil revetment structure under wave action, when the permeability of top layer is poorer than that of filter layer, there will be great uplift force inside the filter layer acting on the top layer.

The parameter $1 /\left(1+4 \pi^{2} \Lambda^{2} / l^{2}\right)$ can be used to conduct quantitative comparison between the water pressure inside the filter layer and wave pressure outside the top layer.

In the using process of top layer-geotextile-filter layer-subsoil revetment structure, as the clogging of top layer or geotextile may result in the decrease of top layer's permeability, the uplift force of filter layer may increase under wave action. Especially when the permeability of filter layer is good, this uplift force change is more obvious. Therefore, the design shall allow for the clogging in practical use and the thickness of top layer shall thus be increased appropriately.

\section{References}

[1] Klein, B. M., and Bezuijen, A. 1998. "Design Criteria for Placed Block Revetments." Dikes and Revetments (Edited by Krystian W. Plarczyk), 217-48.

[2] Yan, T. S. 1996. "Summary and Discussion on Upstream Slope-Protection for Reservoirs on Plains." Water Resources Science and Technology of Shandong: 14-7.

[3] Schiereck, G. J. 1998. "Soil-Water-Structure Interactions." Dikes and Revetments (Edited by Krystian W. Plarczyk), 101-12.

[4] de Groot, M. B., Bezuijen, A., Burger, A. M., and Konter, J. L. M. 1988. "The Interaction between Soil, Water and Bed or Slope Protection." Modeling Soil-Water-Structure Interactions (Edited by Kolkman et al.), 183-97.

[5] Burger, A. M., Breteler, M. K., Banach, L., Bezuijen, A., and Pilarczyk, K. W. 1990. "Analytical Design Method for Relatively Closed Block Revetments." $J$. Waterway, Port, Coastal, Ocean Eng. 116(5): 525-44.

[6] Bezuijen, A., and Breteler, M. K. 1996. "Design Formulas for Block Revetments." J. Waterway, Port, Coastal, Ocean Eng. 6(122): 281-7.

[7] van Gent, M. R. A. 1995. "Porous Flow through Rubble-Mound Material." J. Waterway, Port, Coastal, Ocean Eng. 121(3): 176-81. 